\title{
Religião e consumo nas práticas umbandistas: uma análise do discurso do portal Terra Mystica
}

\section{Ronivaldo Moreira de Souza}

Universidade Paulista, Programa de Pós-Graduação em Comunicação Social, São Paulo, SP, Brasil ORCID: https://orcid.org/0000-0002-2124-9986

\section{Maurício Ribeiro da Silva}

Universidade Paulista, Programa de Pós-Graduação em Comunicação Social, São Paulo, SP, Brasil ORCID: http://orcid.org/0000-0002-7152-2581

\section{Vânia de Toledo Piza}

Universidade Paulista, Programa de Pós-Graduação em Comunicação Social, São Paulo, SP, Brasil ORCID: https://orcid.org/0000-0001-6943-2934

\begin{abstract}
Resumo
O objetivo deste artigo é investigar como se dá a relação entre religião e consumo nas práticas discursivas do portal Terra Mystica, loja virtual identificada com a religiosidade afrobrasileira. Para isto, adotamos como metodologia a Análise do Discurso de Escola Francesa investigando o processo de produção de sentidos que possibilita que esse discurso legitime o seu dizer tanto na esfera religiosa quanto nas práticas de consumo. Constatamos que nesse discurso, religião e consumo se transformam em uma mesma fonte de acesso à experiência com o transcendente.
\end{abstract}

\section{Palavras-chave}

Consumo; Religião; Umbanda; Análise do Discurso

\section{Introdução}

Há muito, a relação entre religião e consumo é estudada tanto por pesquisadores de fenômenos religiosos, quanto por estudiosos das práticas de consumo. Normalmente, os traços dessa relação são mais marcantes e facilmente identificados nas manifestações religiosas midiatizadas.

Neste artigo propomos investigar a incidência dessa relação no Portal Terra Mystica, uma loja virtual identificada com a religiosidade afro-brasileira e que é administrada pelo 
umbandista Pai Rodrigo de Queiroz. 0 fenômeno, por si só, já representa uma importante transformação, pois, sendo uma religião de tradição oral, a migração de suas práticas para o contexto da mídia on-line já implica em importantes mudanças nas práticas ritualísticas para adaptar-se a esse novo contexto.

Para além dessa constatação, a loja virtual ao mesmo tempo em que se alinha à cultura do faça vocês mesmo, tão comum nas mídias digitais sociais, mescla em seu discurso crenças da religião com apelos de consumo tipicamente publicitários objetificando sua doutrina e ritos e oferecendo-os em produtos/serviços para os fiéis/ consumidores.

Desse modo, o objetivo deste trabalho é investigar como se dá a relação entre religião e consumo nas práticas discursivas do portal Terra Mystica. Para isto, adotamos como metodologia a Análise de Discurso de Escola Francesa para apreender o processo de produção de sentidos nesse discurso que compõe o corpus da pesquisa.

Iniciamos nosso texto com uma discussão teórica sobre o consumo e como, gradativamente, as narrativas de consumo se deslocaram da utilidade dos objetos para a satisfação dos desejos. Verificamos nessa perspectiva como as transformações sociais criaram uma imbricada relação entre religião e consumo oferecendo uma transcendência para consumo e um consumo de experiências transcendentes.

Depois fizemos uma breve exposição sobre os pressupostos teórico-metodológicos da Análise do Discurso de Escola Francesa indicando o viés que iriamos adotar na investigação do corpus.

Por fim, aplicamos a metodologia aos textos coletados no portal Terra Mystica analisando o processo de produção de sentidos que possibilitam às práticas religiosas e de consumo se cristalizarem em um mesmo discurso transformando consumo e religião em uma mesma fonte de acesso ao transcendente.

\section{Discussão teórica}

Faremos uma breve discussão teórica para compreender a imbricada relação entre religião e consumo na contemporaneidade que possibilita um espaço de trocas entre religião e mercado no qual a espiritualidade se transforma em produto/serviço para consumo e os objetos de consumo são revestidos de uma aura de sacralidade. Nosso objetivo é apontar a perspectiva pela qual contemplaremos o fenômeno objeto desta pesquisa. 


\subsection{0 consumo do intangível: da utilidade ao significado dos objetos}

As práticas de consumo da sociedade contemporânea são alvo das mais diversas disciplinas das ciências sociais e humanas. Neste tópico, no entanto, faremos uma sucinta abordagem da perspectiva que adotaremos nesse trabalho.

Assumimos dois pressupostos básicos e complementares entre si para nortear nossas considerações: 1) todo consumo é cultural porque sempre envolve significado concordamos com Don Slater (2002, p. 131) que "para 'ter uma necessidade' e agir em função dela precisamos ser capazes de interpretar sensações, experiências e situações e de dar sentido a (bem como de transformar) vários objetos, ações, recursos em relação a essas necessidades"; 2) o que consumimos é, primordialmente, o significado dos objetos, não a sua materialidade - nesse sentindo, concordamos com a formulação de Baudrillard (2008, p. 66) quando afirma que "nunca se consome o objeto em si (no seu valor de uso) - os objetos (no sentido lato) manipulam-se sempre como signos que distinguem o indivíduo, quer filiando-o no próprio grupo tomado como referência ideal, quer demarcando-o do respectivo grupo".

Para compreender melhor que transformações sociais possibilitaram aos objetos de consumo assumir essa dimensão simbólica significativa, precisamos entender as mudanças sociais paradigmáticas que abriram esse espaço no qual os objetos de consumo passaram a atuar.

Campbell (2001, p. 90-91) aponta uma quebra de paradigma na qual a relação carência/satisfação foi substituída pela relação desejo/prazer. 0 modelo carência/satisfação está relacionado com um estado do ser: tem-se uma carência - uma privação de algo necessário à manutenção de uma dada condição de existência -, então, procura-se por algo que seja capaz de suprir essa falta reestabelecendo o equilíbrio. Já o modelo desejo/prazer está relacionado a uma qualidade da experiência, uma disposição motivacional para experimentar sensações que sejam prazerosas. Em outros termos, enquanto a satisfação está ligada ao potencial de utilidade dos objetos e aos seus atributos físicos e materiais, o prazer, além de não ser uma propriedade dos objetos, está ligado à forma como reagimos a certos estímulos

Procurar satisfação é, assim, envolver-se com objetos reais, com o fim de descobrir o grau e a espécie de sua utilidade, enquanto procurar prazer é expor-se a certos estímulos, na esperança de que estes detonarão uma resposta desejada dentro de si mesmo. Por conseguinte, enquanto um, caracteristicamente, precisa usar os objetos a fim de descobrir seu potencial de satisfação, só é necessário a uma pessoa empregar os seus 
sentidos a fim de experimentar prazer e, mais ainda, enquanto a utilidade de um objeto depende do que ele é, a significação agradável de um objeto é uma função do que se supõe que ele seja (CAMPBELL, 2001, p. 91).

Esse novo paradigma permeou toda a vida social alterando as estruturas do consumo. A busca pelo sentido do ser cria um espaço semântico entre o social e o individual, o público e o privado. É nessa região fronteiriça que os objetos assumem a condição de signos. No consumo buscamos principalmente a satisfação das nossas fantasias e expectativas. Enquanto as necessidades se ligam aos aspectos físicos dos bens, o prazer pertence ao mundo da fantasia e da imaginação (TEJON; PANZARINI; MEGIDO, 2010, p. 4-5).

Para León (1998), quando o consumo migra para o campo da fantasia e da imaginação, as narrativas de consumo adotam as estruturas do pensamento mágico. Por pensamento mágico, definimos aquela maneira de entender a realidade não sob o domínio do pensamento empírico, mas sim, por meio da intervenção de seres desconhecidos, superiores e benfeitores, capazes de satisfazer às necessidades humanas que vão além da materialidade e que só podem ser satisfeitas via milagres:

Claro está que na publicidade tudo isto deve ser apresentado como metáfora hiperbólica, ou como milagre tecnológico ou biológico. No primeiro dos casos não é necessário aduzir provas porque estaríamos no terreno da expressão artística e no segundo, as provas têm um caráter pseudocientífico, quer dizer, com aparência científica e realidade fantástica, por exemplo, um creme hidratante 'que detém a passagem do tempo' parece justificar sua afirmação sob o manto da linguagem poética audiovisual e de uns ingredientes de nome ressonantemente 'científico' que em pouco se distanciam dos bálsamos que eram vendidos no século passado para idênticas finalidades (LEÓN, 1998, p. 70. Tradução nossa).

Desse modo, os objetos se transformam na principal forma de expressão paródica do sagrado na publicidade, pois lhe são atribuídas propriedades espirituais capazes de criar uma intersecção entre o material e o espiritual. A magia seria esta "forma de captação da benevolência de seres superiores através de formas e atos rituais para conseguir transformações instantâneas [...] impossíveis de conseguir por meios 'naturais"' (LEÓN, 1998, p. 75. Tradução nossa).

\subsection{0 consumo para a transcendência e a transcendência para consumo}


A percepção de que consumo e religião estabeleciam uma relação cada vez mais próxima já estava presente nos estudos de Belk; Wallendorf; Sherry $(1989$, p. 2) no final da década de 1980. Segundos os autores, "o consumo pode tornar-se um veículo para a experiência transcendente. 0 comportamento do consumidor exibe certos aspectos do sagrado" (Tradução nossa). Muito além de uma relação de simples utilidade, os objetos estabelecem uma relação de reverência e adoração com os consumidores à medida em que são revestidos de virtudes sobrenaturais que transcendem a própria natureza objetificada da mercadoria e, desse modo, supre uma necessidade "de transcender com um mero ser biológico para lidar com o mundo cotidiano" (BELK; WALLENDORF; SHERRY, 1989, p. 2. Tradução nossa).

Tal fenômeno tornou as fronteiras entre sagrado e profano bem mais fluídas, pois o sagrado passa a permear a vida profana, bem como, o profano passa a permear o espaço religioso. Essa reconfiguração gerou uma transformação social importante. Se antes a instituição religiosa eram quem detinha a autoridade para qualificar aquilo que é sagrado, na sociedade de consumo é o consumidor quem passa a ser autorizado para legitimar a distinção entre sagrado e profano a partir da experiência comum

ao invés de experimentar o tipo de significado extraordinário anteriormente alcançado principalmente através da religião, os consumidores contemporâneos definem certos objetos ou experiências de consumo como representando algo mais do que os objetos comuns parecem ser (BELK; WALLENDORF; SHERRY, 1989, p. 13. Tradução nossa).

Indo além nessa discussão é preciso pensar a relação entre religião e mercado não apenas como uma descrição das técnicas mercadológicas adotada pela religião ou das técnicas religiosas adotadas pelo mercado. Se em determinado momento líderes espirituais passam a gerenciar a religião como se fosse uma marca e as marcas passaram a injetar sentimentos religiosos em seus produtos/serviços, logo, existem similaridades que são compartilhadas entre religiões e marcas que vão além de meras apropriações de técnicas (SOLDEVILLA; ERRANDO; FELICI, 2014, p. 67).

Na sociedade contemporânea o consumo está ocupando o espaço do espiritual e do transcendental deixado vago pelas religiões tradicionais institucionalizadas, mas nunca erradicado completamente de sua estrutura mental. Se em um primeiro momento testemunhamos a passagem da economia industrial para a economia de marca, hoje 
presenciamos a transformação da indústria cultural em indústria do transcendental (SOLDEVILLA; ERRANDO; FELICI, 2014, p. 59, 66).

O estudo da relação entre religião e sistema econômico teve em Weber (2004) seu principal precursor quando ele observou que uma determinada ética religiosa havia se tornado fundamental para os interesses expansivos do modelo capitalista vigente. Partindo desse ponto, o autor fez um prognóstico de que o processo de secularização desencadeado pela racionalidade moderna causaria um desencantamento do mundo tornando a religião dispensável e restringindo-a ao campo do privado. Nesse sentido, o próprio sistema econômico, em determinado momento, dispensaria a relação com a religião.

Apesar de concordar a princípio com esse prognóstico de uma secularização ${ }^{1}$ do mundo, Berger (1985) apontou que a religião possuía uma incrível habilidade adaptativa, pois, ao conceber a vida social mundana (nomos) como uma instância submetida ao governo de um mundo espiritual (cosmos), a religião não só desculpabilizava como também sacralizava, por assim dizer, a adoção da lógica do mercado em seu projeto expansivo como um recurso técnico necessário ao avanço de sua missão, fenômeno que denominou de cartelização² (BERGER, 1985, p. 154).

Com a chegada da pós-modernidade e a substituição do modelo carência/satisfação pelo modelo desejo/prazer, a religião precisou reconfigurar-se para adaptar a essa nova realidade social justificando, desse modo, o seu lugar de existência. Bauman afirma que dentro desse novo modelo os desejos humanos são imediatos e urgentes para atender demandas do aqui-e-agora. Desse modo, a religião, que até então se ocupava com questões existenciais tentando responder ao homem seus questionamentos sobre sua origem e destino, passa a lidar com uma sociedade que está mais preocupada com a vida aqui-e-agora do que com questões que antecedem ou sucedem a vida humana. Diante desse fiel desejo de viver a história, não restava à religião outra alternativa senão produzir bens e serviços para esta nova demanda e, porque não dizer, produzir seus próprios consumidores aguçando "as necessidades destinadas a serem satisfeitas pelos seus serviços e, desse modo, tornar seu trabalho indispensável" (BAUMAN, 1998, p.210).

Nessa mesma linha, Lipovetsky (2007) observou que o valor da religião na contemporaneidade não se constitui mais a partir da prerrogativa de auto afirmar-se como

\footnotetext{
1 Mais tarde o autor escreve defendendo a ideia de dessecularização do mundo e admitindo que a teoria da secularização não se sustentava diante da efervescência das formas de religiosidade emergentes. (BERGER,2000).

2 Berger observou ainda na década de 1960 que determinadas agências religiosas entravam em uma espécie de acordo dividindo entre si territórios e nichos de mercado para otimizar a aplicação de seus recursos financeiros e estratégicos para expansão. Daí a ideia de uma cartelização.
} 
uma verdade absoluta, mas sim, da sua virtude em conduzir o sujeito a um estado superior de ser, uma vida melhor e mais autêntica. Ou seja, para sobreviver e justificar sua existência dentro do modelo desejo/prazer, característico da sociedade de consumo, a religião precisou transformar-se em uma prestadora de serviços cujo objetivo é levar o sujeito a encontrar-se consigo mesmo na vida mundana:

Na sociedade de hiperconsumo, mesmo a espiritualidade é comprada e vendida [...]. Eis que a espiritualidade se tornou mercado de massa, produto a ser comercializado, setor a ser gerido e promovido [...]. Hoje, mesmo a espiritualidade funciona em auto-serviço, na expressão das emoções e sentimentos, nas buscas animadas pela preocupação com o maior bem-estar pessoal (LIPOVETSKY, 2007, p.132-133).

Nesse ponto chegamos a uma importante chave de leitura para a relação entre religião e mercado na contemporaneidade. Eliade (1992) observou que o sagrado era uma manifestação sobrenatural em objetos comuns da vida cotidiana, fenômeno que denominou de hierofania: "a pedra sagrada, a árvore sagrada não são adoradas como pedra, ou como árvore, mas justamente porque são hierofanias, porque 'revelam' algo que já não é nem pedra, nem árvore, mas o sagrado" (ELIADE, 1992, p.13).

Desse modo, na esteira da discussão teórica até aqui apresentada, podemos pensar o consumo na contemporaneidade como hierofanias, já que as narrativas de consumo a todo momento se esforçam para transformar objetos da vida cotidiana em elementos sacralizados que são desejados não mais pela sua constituição física, mas sim, por aquilo neles que não é mais o objeto e, sim, seu significado.

Sob a mesma lógica, porém, em uma ordem inversa, a religião passa a objetificar o aspecto transcendente de seus ritos, doutrinas e crenças, dispondo-os aos fiéis como objetos de consumo e que passam a ocupar um lugar de imanência na vida cotidiana.

Em outros termos, o mercado subjetiva seus produtos/serviços envolvendo-os numa aura de sacralidade, dispondo para o consumidor um consumo da transcendência. A religião objetifica sua doutrina, ritos e credos oferecendo aos fiéis/consumidores por meio de seus produtos/serviços uma transcendência para consumo. Religião e mercado são duas vias possíveis de satisfazer a um mesmo desejo ontológico do ser humano de experimentar o sagrado. 


\subsection{Ritos e crenças da Umbanda: da tradição oral a práticas midiatizadas}

A umbanda é uma religião afro-brasileira fundada na ideia do mediunismo - suposta capacidade de uma pessoa incorporar e emprestar o seu corpo, fala e gestos e ser intérprete do pensamento de um espírito.

Concebida no início do século XX, apresenta influência do catolicismo, espiritismo, religiões africanas como o candomblé, bem como de elementos da cultura indígena. Reflexo de seu sincretismo, a Umbanda é diversificada apresentando diferentes vertentes que têm relação direta com a liberdade da organização ritualística e administrativa de seus templos, por meio de diversas formas de se praticar e vivenciar a Umbanda.

A despeito disso, a Umbanda trabalha centrada na existência de Deus e opera unanimemente em um sistema de práticas simbólicas e de crenças relativas ao mundo invisível por meio de entidades espirituais - os caboclos e os pretos-velhos - e orixás, como Ogum, Oxum e Iemanjá, dentre outros, que se manifestam por meio da incorporação em um médium objetivando a pratica da caridade, aconselhamento espiritual e acolhimento aos adeptos da religião.

Em ocorrendo este fenômeno, por mais que existam outros elementos como música, atabaque e ações complementares substanciais, o ápice do ritual ocorre no diálogo entre o adepto e o médium incorporado, ou seja, as questões da vida, quer materiais ou espirituais, são tratadas nessa relação. As orientações para o adepto são supostamente apresentadas diretamente pelo espírito, sem um intermediário que fale em nome desse espírito. Em outras religiões, este contato direto não ocorre, como no caso do sacerdote que fala em nome de Deus, mas ainda preserva toda sua personalidade e subjetividade pessoal no exercício do sacerdócio. Na Umbanda crê-se que o espírito incorporado apresenta sua própria subjetividade, gestos, falas e traços da personalidade quando apropria-se da materialidade corpórea do médium.

Apesar de firmar-se como uma religião de tradição oral, a Umbanda está inserida no contexto contemporâneo da midiatização do cotidiano o que implica na centralidade da mídia como parte integrante do processo de vida dos indivíduos, como uma nova "forma de sociabilidade":

A midiatização deve ser pensada como tecnologia de sociabilidade ou um novo bios, uma espécie de quarto âmbito existencial onde predomina (muito pouco aristotelicamente) a esfera dos negócios, com uma qualificação cultural própria (a tecnocultura). 0 que já se fazia presente, 
por meio da mídia tradicional e do mercado, no ethos abrangente do consumo, consolida-se hoje com novas propriedades por meio da técnica digital... é que a tecnocultura - essa constituída por mercado e meios de comunicação, a do quarto bios - implica uma transformação das formas tradicionais de socialização, além de uma nova tecnologia perceptiva e mental. Implica, portanto, um novo tipo de relacionamento do indivíduo com referências concretas ou com o que se tem convencionado designar como verdade, ou seja, uma outra condição antropológica (SODRÉ, 2006, p. 25-26).

Em consequência, a cultura midiática intensifica os fenômenos de produção e de significados para a sociedade constituindo novos espaços identitários. Para que isso ocorra, conta com diferentes e diversificados protagonistas, dentre eles os próprios indivíduos, bem como instituições, como as religiosas, que antes não operavam efetivamente em certos canais de comunicação.

Por meio desse fenômeno de midiatização da sociedade, a Umbanda tem intensificado a sua comunicação, principalmente nos meios digitais, por envolver baixo investimento e possibilitar alta penetração, alcance, frequência de exposição e interatividade. Produtos e serviços relacionados à Umbanda, de diversos matizes, têm sido oferecidos e comercializados na internet, interferindo, inclusive, no ritual tradicional da religião.

Tome-se como exemplo a primeira plataforma de estudos on-line sobre a Umbanda, a Umbanda EAD, criada em 2006 pelo Sacerdote Pai Rodrigo Queiroz, Diretor e Tutor da Umbanda EAD que, segundo divulgação própria, já formou mais de 30 mil alunos.

Esse Sacerdote Pai comercializa, por meio de sua loja virtual Terra Mystica (TERRA MÍSTICA, 2020a ), produtos da ritualística umbandista para que o próprio fiel pratique os rituais em sua casa em consonância com a cultura do "faça você mesmo".

\section{Metodologia}

Adotaremos como metodologia desta pesquisa a Análise do Discurso (AD) de Escola Francesa que, segundo Brandão (2004, p. 38), estabelece suas bases epistêmicas em três áreas do conhecimento: o materialismo histórico, a linguística e a teoria do discurso.

A AD parte do pressuposto de que o sentido é o ponto nodal entre a linguística, a filosofia e as ciências sociais. Sendo assim, "a finalidade do analista do discurso não é interpretar, mas compreender como um texto funciona, ou seja, como um texto produz sentidos" (ORLANDI, 2011, p.19). 
Esse pressuposto representa um avanço em relação aos estudos que precederam a $\mathrm{AD}$ e compreendiam a linguagem ora como uma ferramenta - um instrumento pronto e à disposição para o uso dos emissores -; ora como um meio para um fim: nomear coisas e descrever o mundo. Ao contrário disso, a $\mathrm{AD}$ adotou uma "convicção da importância central do discurso na construção da vida social [...] e rejeitou a noção do sujeito unificado coerente, que foi ao longo do tempo o coração da filosofia ocidental" (GILL, 2002, p. 245-246).

Nesse sentido, pela concepção que tem da linguagem e do discurso, a AD não se ocupa com a função da língua, mas sim, com o seu funcionamento, com o processo de produção de um discurso que é "o conjunto de mecanismos formais que produzem um discurso de tipo dado em 'circunstâncias' dadas" (PÊCHEUX, 1997, p. 74).

A Análise do Discurso não deve ser tomada como uma ciência hermenêutica cujo objetivo é descobrir o sentido de um texto, ou ainda, responder à pergunta: "o que o autor quis dizer?". Pelo contrário, ela se propõe a descrever os processos que tornam possíveis os sentidos de um determinado discurso. Maingueneau (1997, p.13-14) afirma que para atingir esse objetivo a $\mathrm{AD}$ precisa basear sua análise em três dimensões: o quadro das instituições que restringem fortemente a enunciação; os embates históricos e sociais que se cristalizam no discurso; o espaço próprio que o discurso configura para si no interior de um interdiscurso.

Percebe-se que a $\mathrm{AD}$ sustenta a ideia de que todo discurso é circunstancial. Em outros termos, o analista parte do pressuposto de que o discurso cristaliza práticas que são culturais e sociais e não as intenções confinadas na cabeça de alguém (PISA; SOUZA; VIZIBELI, 2018, p.18).

Portanto, o analista deve abandonar o pressuposto de que o discurso que vai analisar é uma produção de um determinado sujeito. Pelo contrário, ao compor o corpus de análise deve-se "considerar sua enunciação como o correlato de uma certa posição sóciohistórica na qual os enunciadores se revelam substituíveis" (MAINGUENEAU, 1997, p.14).

No caso desta pesquisa, o corpus selecionado foi o discurso para venda dos produtos/serviços no portal www.terramystica.com, administrado pelo sacerdote umbandista Rodrigo Queiroz. Interessa-nos, principalmente, o discurso para venda de produtos destinados a práticas ritualísticas como velas, ervas e a caixa mystica. Nosso objetivo é verificar como a relação entre religião e consumo se cristaliza nos discursos do supracitado portal. 


\section{Resultados}

Fundado em março de 2014 por Rodrigo Queiroz e Thaís Helena Queiroz, o portal Terra Mystica propõe convergir "para um mesmo espaço produtos diversos da ritualística umbandista e do holismo em geral, da melhor qualidade, com a melhor negociação e atendimento especializado" (TERRA MYSTICA, 2020b).

Os idealizadores atestam a qualidade dos produtos que comercializam, não apenas do ponto de vista de sua composição material, mas também de sua eficácia no universo espiritual: "Os itens que são oferecidos nesta vitrine virtual passam por um rigoroso crivo de testes, verificações e qualidade, para que realmente sejam eficazes e úteis para aquilo que se propõem". Mas o principal argumento desse discurso de apresentação dos produtos/serviços dispostos para consumo, e que busca justificar o seu lugar de existência tanto no universo mercadológico quanto no universo religioso, é que a loja virtual usa "a tecnologia e a inspiração espiritual com foco no relacionamento humano devotado ao Sagrado"( TERRA MYSTICA, 2020b). Esse argumento aparece implícita ou explicitamente na apresentação de quase todos os produtos/serviços comercializados no portal, ora falando das propriedades físicas dos objetos, ora falando de sua natureza imaginária, fantástica e mágica como mediadora de uma relação com o sagrado.

No alto da página um sistema dinâmico apresenta um texto que traz por título "Nossos 7 pilares", como se vê na imagem abaixo:

Figura 1 - Apresentação dos ideais do portal
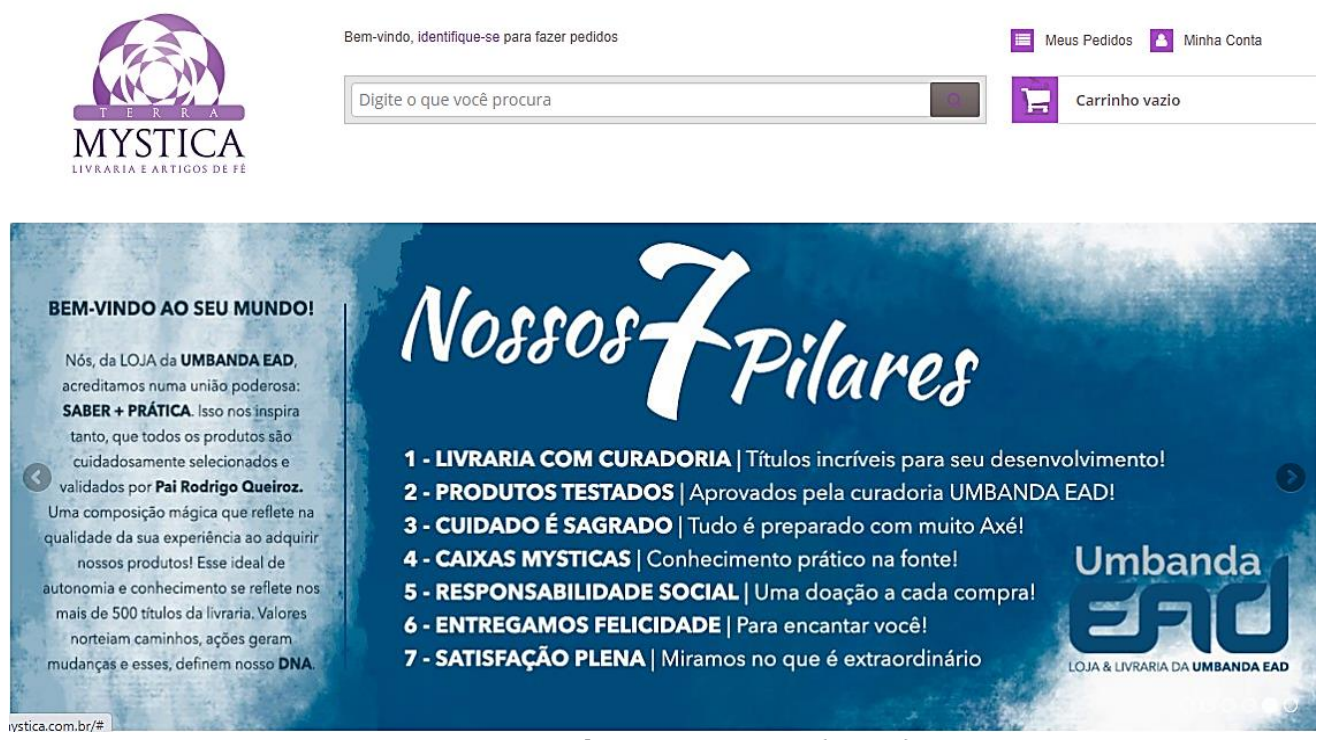

Fonte: Portal Terra Mystica (2020). 
O texto mescla o discurso mercadológico e o religioso na oferta de produtos e serviços com a promessa de proporcionar um encontro com o sagrado, uma experiência transcendente. Primeiramente vale notar como o discurso mantém características tipológicas do discurso religioso que, segundo Maingueneau, opera por um sistema de validação peculiar que no próprio ato de enunciação, em um mesmo movimento, se apropria de outros discursos e apaga as marcas dessa interdiscursividade

Discursos como o religioso [...] se definem pela posição que ocupam no interdiscurso, pelo fato de não reconhecerem discursividade para além da sua e de não poderem se autorizar senão por sua própria autoridade. [...] para não se autorizarem apenas por si mesmos, devem aparecer como ligados a uma Fonte legitimadora. Eles são ao mesmo tempo auto e heteroconstituintes (MAINGUENEAU, 2008, p. 38-39).

Entendendo que o discurso é o lugar onde as práticas sociais se cristalizam, notamos que o sistema de validação do discurso também se manifesta na própria prática religiosa. Podemos notar que a qualidade e eficácia dos produtos são validados por um sistema próprio de validação, como afirma o texto à esquerda na imagem: "todos os produtos são cuidadosamente selecionados e validados por Pai Rodrigo Queiroz" (Grifo do autor). Na expressão em destaque no texto, o lugar de fala se desloca do empreendedor para o sacerdote. Quem valida o produto não é o homem de negócios, mas sim, o Pai de Santo.

É esse duplo lugar de fala que se alterna ao longo do texto que torna possível, ora uma promessa de certificação qualitativa advinda das propriedades materiais do objeto e que tem como fiadora uma marca comercial - "aprovados pela curadoria UMBANDA EAD" -; ora da eficácia do produto em proporcionar uma experiência com o sagrado tendo como fiador desse discurso o sacerdote Pai Rodrigo de Queiroz - "É sagrado - tudo é preparado com muito Axé [...]; miramos no que é extraordinário".

Esse movimento de alternância possibilita ao enunciador afirmar: "entregamos felicidade - para encantar você". 0 argumento propicia um efeito de hierofania disponibilizando para o consumidor/fiel aquilo que não é mais o produto, mas sim, a sua transcendência e o mundo de sentidos ao qual ele dá acesso. A base dessa proposta argumentativa retorna ao elemento religioso e ao sistema de crenças interno à religião umbandista: "uma composição mágica que reflete na qualidade de sua experiência ao adquirir nossos produtos".

Esse processo de produção de sentidos torna-se ainda mais interessante quando observamos os textos de apresentação dos variados produtos comercializados no portal. 
Quando o objeto disposto para consumo tem seu significado e simbolismo bem consolidado no sistema de crença, o texto se abdica de falar sobre seu valor simbólico e concentra-se nas suas propriedades físicas, pois são elas que diferenciam esse produto comercializado pela loja virtual dos demais concorrentes.

Observa-se como um exemplo disso, a venda das velas utilizadas nos rituais de Firmeza. Busca-se, por meio da Firmeza, a força originária do poder dos orixás e das entidades da Umbanda, a partir da utilização de velas, pembas, ervas e outros elementos que são acionados para o alcance de variadas demandas, como saúde, amparo e proteção. Ao acender uma vela a determinado orixá, por exemplo, firma-se uma força, a do poder do orixá. Aconselha-se que este processo seja realizado em ambiente apropriado e que o adepto tenha fé e convicção no ritual e na força de sua representatividade. Se assim for, acredita-se que naquela vela há uma força firmada, uma vez que firmar significa que tal força vibrará e repercutirá enquanto a vela estiver acessa. A Firmeza é provisória. No caso da vela, enquanto estiver acesa ela estará firmada. Uma vez apagada, essa conexão deixa de ocorrer.

Essas velas são oferecidas no portal com o seguinte texto:

Velas de 7 dias votiva com qualidade premium e especiais. Produzidas com parafina pura Petrobrás, garantia de queima perfeita e segurança.

AVISO IMPORTANTE: Trata-se de uma vela votiva de até sete dias de queima, podendo variar para um pouco mais ou menos considerando as variáveis, tais como: circulação de ar, pigmentação específica, fragmento de plástico ou impureza que caia no pavio aumentando a chama, furo no plástico que permita a cera líquida escorrer aumentando a queima. A variação no tempo de queima não configura defeito no produto. Média de variação na queima total - 5 a 8 dias (TERRA MYSTICA, 2020c).

Nota-se que o enunciador parte do pressuposto que o consumidor/fiel tenha conhecimento do ritual e da crença e, desse modo, dedica-se a descrever os atributos físicos do objeto: "qualidade premium [...]. Produzidas com parafina pura Petrobrás, garantia de queima perfeita e segurança". Em outros termos, a natureza distintiva do produto recai, nesse caso, sobre sua composição material, já que muitas velas poderiam ser utilizadas para a prática do ritual, no entanto, apenas as velas comercializadas pelo portal Terra Mystica têm propriedades distintivas como "parafina pura Petrobrás".

Em outros produtos, como é o caso das ervas, por exemplo, o texto de apresentação do produto reforça seu valor simbólico para além de seus atributos físicos. Citamos como exemplo o texto de exposição do Bastão Xamânico Sálvia Branca: 
A palavra Sálvia tem origem no latim Salvare, significa saúde e evoca a cura.Esta poderosa planta sagrada é utilizada há milhares de anos pelos nativos norte-americanos em rituais espirituais. Ela é considerada a planta da imortalidade e cresce de maneira selvagem nos desertos do oeste dos Estados Unidos até o Novo México. O BASTÃO XAMÂNICO SÁLVIA BRANCA tem o poder de limpeza e purificação, é uma das melhores plantas utilizadas para esta finalidade que a nossa Mãe Natureza nos oferta, e seu aroma é único. Bem-estar, paz, força vital e alegria são as energias que se espalham pelos ares em que a planta se expande (TERRA MYSTICA, 2020d, Grifos do autor).

Nesse caso, em especial, é interessante verificar como a natureza transcendente do produto justifica seu valor de venda para o fiel. Nos comentários dessa página encontramos o seguinte diálogo entre os consumidores:

CONSUMIDOR 1: nossa que erva cara em? eu compro salvia na feira deixo secar e uso na defumação e compro super barato.

CONSUMIDOR 2: é salvia Branca, é diferente da encontrada por ai CONSUMIDOR 3: Qual a diferença?

CONSUMIDOR 4: o perfume a energia é muito diferente. Um é de temperar comida a outra é de limpeza energética (TERRA MYSTICA, 2020d).

A natureza transcendental do produto justifica a discrepância no valor monetário que se cobra por ele em comparação ao outro adquirido em qualquer outra casa de comercialização de ervas. Vale ressaltar que nesse caso específico a marca não intervém no diálogo que se mantém entre os próprios consumidores e que argumentam em favor da eficácia do produto em sua capacidade de proporcionar uma experiência com o sagrado.

\subsection{A Caixa Mystica}

A Caixa Mystica é um produto semelhante aos comercializados pelos meios digitais por Clubes de Assinatura. O Clube de Assinatura é um modelo de negócio de varejo totalmente voltado ao Empreendedorismo Digital. Trata-se de planos com periodicidade variada que permitem ao assinante receber em casa uma caixa com uma seleção de produtos de determinada categoria. Há um modelo complementar de negócio que comercializa uma caixa especial, a "Mistery Box". Como o próprio nome indica, esta caixa oferece produtos surpresa de acordo com determinado tema. Neste caso, a empresa cobra pela caixa por compra individual e não pelo modelo de Clube. A Caixa Mystica, com produtos da Umbanda, se enquadra neste último modelo de negócio. 
A cada mês, a loja Virtual Terra Mystica oferece uma caixa com uma entidade diferente sempre relacionada ao ritual da Firmeza. As caixas trazem temáticas como: Ogum, Xangô, Orixás, Exú e Pombagira, Pretos-Velhos e Caboclos.

Vamos tomar como exemplo a Caixa Mystica Ogum. A composição do discurso imagético de apresentação do produto evoca a crença mágica que é um dos fundamentos da religiosidade umbandista. Os raios coloridos saindo de dentro da caixa situam o produto em um outro universo que vai além de sua aparência rústica composta de um simples material feito de papelão. O livro com a imagem que remete a São Jorge complementa esse deslocamento espaço temporal entre sagrado e profano.

Figura 2 - Caixa Mystica

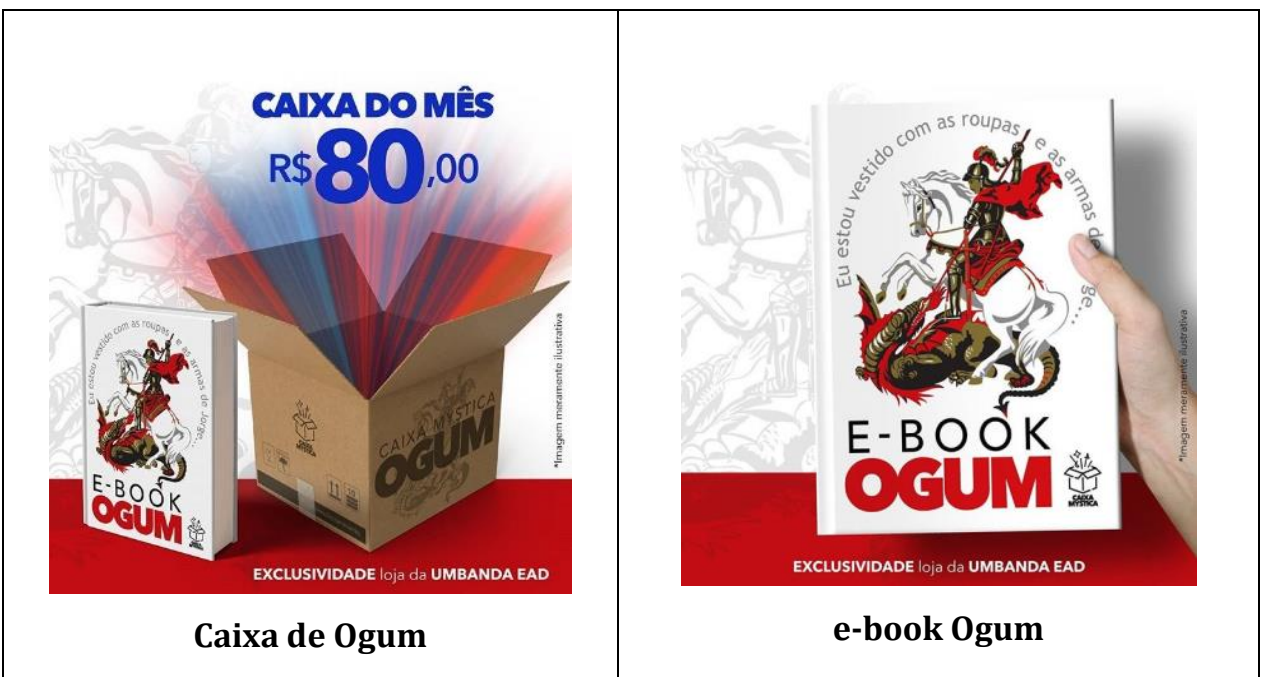

Fonte: Portal Terra Mystica (2020e).

O texto de apresentação do produto diz o seguinte:

A Caixa Mystica Ogum são 7 dias para ritualizar em casa acompanhado com e-book elaborado por Pai Rodrigo Queiroz - Umbanda EAD para aprofundar seus conhecimentos através da prática com nosso Guerreiro Valente. Preparamos este "kit firmeza" para você aproveitar a oportunidade de ser inspirado e positivamente influenciado por esta Divindade, ter seu corpo espiritual fortalecido, purificado e renovado em potência e coragem, força e determinação, neste mês dedicado a Pai Ogum na Umbanda em função do sincretismo com São Jorge.

\section{---- DÚVIDAS FREQUENTES ------}

QUEM PODE FAZER O RITUAL?

Qualquer pessoa que tenha interesse em atrair e ativar a força positiva e poderosa de Pai Ogum estão empoderados através deste conhecimento prático e público. Esta é uma instrução religiosa ensinada pelo Sacerdote 
Pai Rodrigo Queiroz, Diretor e Tutor da Umbanda EAD. Não existe nenhum pré-requisito ou efeito colateral.

\section{PODE FAZER FIRMEZA EM CASA?}

A firmeza para o religioso Umbandista é o mesmo que orar, rezar. Trata-se do relacionamento prático com o Sagrado. Caso você queira acreditar que o Sagrado não pode habitar seu lar, realmente é melhor não se permitir a esta experiência maravilhosa, libertadora e purificadora.

\section{POSSO CONFIAR?}

Pai Rodrigo Queiroz já impactou em seus estudos mais de 30 mil Umbandistas através da plataforma Umbanda EAD, é um dos tutores mais procurados da religião e autor dos estudos mais originais sobre Mediunidade, Linhas de Trabalho e religiosidade Umbandista da atualidade.

\section{O QUE CONTÉM A CAIXA MYSTICA?}

A Caixa Mystica pode conter itens como velas, incensos, resinas, ervas, pedras, guias e entre outros, necessários para ritualizar em casa. Não são informados os elementos para que sua experiência seja sempre uma agradável surpresa! (TERRA MYSTICA, 2020e, Grifos do autor)

Destacamos, primeiramente, que o texto começa com um apelo centrado na cultura do "faça você mesmo" indicando que se trata de um produto "para ritualizar em casa". No entanto, o mesmo argumento que poderia indicar a desnecessidade da mediação do sacerdote, já que cada indivíduo poderá fazer o rito em sua própria casa, volta-se para a importância do pai de santo, já que o e-book, que parece funcionar como uma espécie de manual para o ritual, foi "elaborado por Pai Rodrigo Queiroz - Umbanda EAD para aprofundar seus conhecimentos através da prática com nosso Guerreiro Valente". 0 sacerdote e a marca constituem um mesmo discurso de validação do objeto de consumo atestando seu valor religioso e mercadológico.

Em seguida, o produto é apresentado como uma prestação de serviços da marca para o consumidor: "Preparamos este 'kit firmeza' para você aproveitar a oportunidade". A eficácia espiritual do produto e sua natureza transcendente é ressaltada no mesmo parágrafo.

A partir desse ponto, observamos uma estratégia discursiva de "antecipação do dizer do outro". Esse movimento discursivo evoca um enunciador onisciente que, porque conhece os anseios e desejos de seu enunciatário, pode antecipar-lhe as dúvidas e questionamentos respondendo-as. A proposta é suscitar a ideia de uma marca ou produto que é empática com seus consumidores, pois os conhece.

A primeira pergunta, "quem pode fazer o ritual?", mescla em uma mesma resposta a universalidade do produto e sua singularidade. 
Qualquer pessoa que tenha interesse em atrair e ativar a força positiva e poderosa de Pai Ogum estão empoderados através deste conhecimento prático e público. Esta é uma instrução religiosa ensinada pelo Sacerdote Pai Rodrigo Queiroz, Diretor e Tutor da Umbanda EAD. Não existe nenhum pré-requisito ou efeito colateral. (TERRA MYSTICA, 2020e)

Ao mesmo tempo que "qualquer pessoa pode fazer", o texto singulariza o produto e seu consumidor já que esse "qualquer pessoa" se restringe ao grupo dos que são "empoderados" pelo conhecimento e instrução do sacerdote disposta para consumo pela marca Umbanda EAD. Por fim, para esse grupo seleto, não existe nenhum efeito colateral, nem pré-requisito, exceto, é claro, o de pertencer ao grupo dos filiados à marca.

A resposta à segunda pergunta, "pode fazer firmeza em casa?", adota uma estratégia de provocação e desafio. Após simplificar a prática da firmeza comparando-a com orar e rezar, o enunciador faz uma provocação à capacidade de crer do fiel/consumidor: "Caso você queira acreditar que o Sagrado não pode habitar seu lar, realmente é melhor não se permitir a esta experiência maravilhosa, libertadora e purificadora". A formulação do pensamento deixa o enunciatário em um dilema questionando a sua capacidade de crer. A ação de comprar o kit para a prática do ritual transforma-se, também, em uma forma de expressão de fé do fiel/consumidor.

Em resposta à pergunta "posso confiar?", o enunciador evoca critérios quantitativos que podem certificar a expertise do Pai Rodrigo de Queiroz como sacerdote e a marca Umbanda EAD como referência em tutoria para prática da religião. A construção desse parágrafo no texto é muito significativa, pois apesar da pergunta remeter à eficácia dos produtos e do ritual, nada é dito sobre isso, pelo contrário, todo o foco recai sobre a pessoa do sacerdote e da marca Umbanda EAD. Marca e ritual, sagrado e profano, se misturam de maneira tão fluída que a marca se transforma no lugar de imanência onde a transcendência do sagrado se manifesta. A marca se torna fiadora da religião.

A última pergunta é sobre o conteúdo da Caixa Mystica. A resposta, apesar de oferecer indícios, cria expectativa e constrói mistério em torno do produto. Após garantir que ela contém produtos necessários para ritualizar em casa, o texto conclui que "não informar" é, também, uma prestação de serviços ao fiel/consumidor "para que sua experiência seja sempre uma agradável surpresa!". O mistério compõe a personalidade do produto que traz em seu nome sua prerrogativa mística. 


\section{Considerações finais}

Esta pesquisa nos possibilitou ver a relação entre religião e consumo nas práticas comerciais e religiosas do portal Terra Mystica. A relação entre religião e marca se cristaliza no discurso ressignificando, em um mesmo movimento, as práticas religiosas e de consumo.

Verificamos que o corpus selecionado para esta pesquisa evidencia transformações sociais constituídas ao longo das últimas décadas. De um lado práticas religiosas menos transcendentes e mais voltadas para as demandas de uma sociedade imediatista. Do outro, práticas de consumo que apelam para esse lugar do transcendente deixado vago pela religião. Nesse ponto, religião e consumo estabelecem uma imbricada relação na qual, por um lado, se produz uma transcendência para consumo e, por outro, um consumo de transcendência. 0 mercado subjetivando seus produtos e revestindo-os de uma aura de sacralidade; e a religião objetificando sua doutrina e seus ritos, dispondo-os como produtos e serviços para consumo. Caminhos diferentes para satisfazer a um mesmo desejo ontológico do ser humano: ter uma experiência com o sagrado.

Esperamos que o caminho aqui percorrido possa servir de ponto de partida para futuros pesquisadores cujo o objeto de estudo seja a relação entre religião e consumo nas práticas sociais, especialmente na América Latina.

\section{Financiamento}

O presente trabalho foi realizado com apoio da Coordenação de Aperfeiçoamento de Pessoal de Nível Superior - Brasil (CAPES) - Código de Financiamento 001.

\section{Referências}

BAUDRILLARD, Jean. A sociedade de consumo. Lisboa: Edições 70, 2008.

BAUMAN, Zygmunt. 0 mal-estar da pós-modernidade. Rio de Janeiro: Jorge Zahar, 1998.

BELK, Russell W.; WALLENDORF, Melanie; SHERRY, John F. Jr. The Sacred and the Profane. in: Consumer Behavior: Theodicy on the Odyssey. The Journal of Consumer Research, Chicago, Vol. 16, No. 1. Jun.1989. The University of Chicago. p. 1-38.

BERGER, Peter Ludwig. 0 dossel sagrado: elementos para uma teoria sociológica da religião. São Paulo: Paulinas, 1985. 
BERGER, Peter. A dessecularização do mundo: uma visão global: Religião e Sociedade, Rio de Janeiro, vol. 21, no1, 2000. p. 9-24.

BRANDÃO, Helena Hathsue Nagamine. Introdução à análise do discurso. Campinas: Editora da Unicamp, 2004.

CAMPBELL, Colin. A ética romântica e o espírito do consumismo moderno. Rio de Janeiro: Rocco, 2001.

ELIADE, Mircea. 0 sagrado e o profano. São Paulo: Martins Fontes, 1992.

GILL, Rosalind. Análise de discurso. In: BAUER, Martin W.; GASKELL, George (ED). Pesquisa qualitativa com texto, imagem e som: um manual prático. Petrópolis: Vozes, 2002.

LEÓN, José Luiz. Mitoanálisis e ideología de la publicidade. Revista Comunicación \& cultura, España, №. 3, 1998, p. 65-78.

LIPOVETSKY, Gilles. A felicidade paradoxal: ensaio sobre a sociedade de hiperconsumo. São Paulo: Companhia das Letras, 2007.

MAINGUENEAU, Dominique. Cenas da enunciação. São Paulo: Parábola Editorial, 2008.

MAINGUENEAU, Dominique. Novas tendências em Análise do Discurso. Campinas: Pontes; Editora da Universidade Estadual de Campinas. 3o edição, 1997.

ORLANDI, Eni Pulcinelli. Discurso e texto: formulação e circulação dos sentidos. Campinas: Pontes, 2011.

PÊCHEUX, Michel. Análise automática do discurso (AAD-69). In: GADET, Françoise; HAK, Tony. Por uma análise automática do discurso: uma introdução a obra de Michel Pêcheux. Campinas: Editora da Unicamp, 1997.

PISA, Lícia Frezza; DE SOUZA, Ronivaldo Moreira; VIZIBELI, Danilo. Análise do discurso: Conceitos e aplicações. Pouso Alegre: IFSULDEMINAS/Lume Editora, 2018.

SLATER, Don. Cultura do consumo \& modernidade. São Paulo: Nobel, 2002.

SODRÉ , Muniz. Antropológica do Espelho. Rio de Janeiro: Ed. Vozes, 2006.

SOLDEVILLA, Samuel Gil; ERRANDO, José Antonio Palau; FELICI, José Javier Marzal. Brands as new forms of religiosity: the case of the word of red bull. Trípodos: llenguatgepensament-comunicació. Universitat Ramon Llull. Facultat de Comunicació i Relacions Internacionals Blanquerna. Barcelona, 2014, número 35. p. 57-74.

TEJON, José Luiz; PANZARINI, Roberto; MEGIDO, Victor. Luxo for all: como atender aos sonhos e desejos da nova sociedade global. São Paulo: Editora Gente, 2010.

TERRA MÍSTICA. Disponível em: https://www.terramystica.com.br/. Acesso em Maio de 2020a. 
TERRA MYSTICA. Bastão Xamânico Salvia Branca Grande. Disponível em: https://www.terramystica.com.br/bastao-xamanico-salvia-branca-grande-. Acesso em Maio de 2020d.

TERRA MYSTICA. Caixa Mystica Ogum. Disponível em:

https://www.terramystica.com.br/caixa-mystica-ogum. Acesso em Maio de 2020 e.

TERRA MÍSTICA. Nossos 7 pilares. Disponível em: https://www.terramystica.com.br/. Acesso em Maio de 2020.

TERRA MYSTICA. Sobre a loja. Disponível em:

https://www.terramystica.com.br/pagina/sobre-loja.html. Acesso em Maio de 2020 b.

TERRA MYSTICA. Vela 7 dias. Disponível em: https://www.terramystica.com.br/vela-7dias-ouro. Acesso em Maio de 2020 c.

WEBER, Max. A ética protestante e o "espírito" do capitalismo. São Paulo: Companhia das Letras, 2004.

\title{
Religion and consumption in Umbanda practices: an analysis of the discourse of the Terra Mystica portal
}

\begin{abstract}
The purpose of this article is to investigate how the relationship between religion and consumption occurs in the discursive practices of the Terra Mystica portal, a virtual store identified with Afro-Brazilian religiosity. To this end, we adopted the French School Discourse Analysis methodology, investigating the process of producing meanings that enables this discourse to legitimize its speech both in the religious sphere and in consumer practices. We found that in this discourse, religion and consumption become the same source of access to the experience with the transcendent.
\end{abstract}

\section{Keywords}

Consumption; Religion; Umbanda; Speech analysis

\section{Autoria para correspondência}

Ronivaldo Moreira De Souza

ronivaldomds@gmail.com 


\section{Como citar}

SOUZA, Ronivaldo Morira de; SILVA, Maurício Ribeiro da; PIZA, Vânia de Toledo. Religião e consumo nas práticas umbandistas: uma análise do discurso do portal Terra Mystica. Intexto, Porto Alegre, n. 52, e104566, jan./dez. 2021. DOI: http://dx.doi.org/10.19132/1807-8583202152.110677

Recebido em 14/01/2021

Aceito em 01/04/2021 